\title{
Prevalence of illicit tobacco use and tobacco tax avoidance in pregnancy
}

\author{
Brendan P. McDonnell ${ }^{1,2}$ (D) $\cdot$ Robert McCausland ${ }^{1} \cdot$ Sheila Keogan $^{3} \cdot$ Luke Clancy $^{3} \cdot$ Carmen Regan $^{1,2}$
}

Received: 5 November 2020 / Accepted: 16 December 2020 / Published online: 13 January 2021

(C) Royal Academy of Medicine in Ireland 2021

\begin{abstract}
Background Smoking during pregnancy is associated with adverse maternal and fetal outcomes. Tobacco tax avoidance and tax evasion undermine the effectiveness of tobacco tax policies, resulting in cheaper prices for smokers and increased tobacco usage. Aims The purpose of this study was to explore the purchasing habits of pregnant smokers with regard to tobacco expenditure and use of illicit tobacco.

Methods Prospective cohort study. Face to face interviews were conducted with 90 attendees (age range 18-42 years; mean age 28 years) of a smoking cessation antenatal clinic in a large Irish tertiary level maternity hospital. Information regarding smoking habits, quantity of tobacco smoked, and location of purchase of tobacco was collected in addition to socioeconomic details. Tobacco products were examined to establish whether these were purchased from legitimate sources.

Results $76.6 \%$ of women smoked 10 or fewer cigarettes per day. The mean weekly spend on tobacco was $€ 39$. Seventeen women (18.8\%) smoked roll-your-own tobacco. One woman (1.1\%) currently possessed a pack of illicit tobacco, while another $5.5 \%$ of participants had purchased illicit tobacco in the past. Four women (4.4\%) practiced tobacco tax avoidance by purchasing tobacco abroad or in Duty Free.

Conclusions Use of illicit tobacco is low and only a minority of women engaged in tobacco tax avoidance. As the average price of tobacco in Ireland increases, weekly expenditure on tobacco products is a significant financial impact on low-income women. Smoking cessation would deliver significant financial gains in addition to health benefits.
\end{abstract}

Keywords Illicit tobacco $\cdot$ Pregnancy $\cdot$ Smoking $\cdot$ Tobacco tax avoidance

\section{Introduction}

The use of taxation to increase the price of tobacco is a key element of tobacco control. Tobacco taxation is highly effective in encouraging cessation and reducing initiation of smoking [1]. The MPOWER package of tobacco control policies is a program of six objectives promoted by the World Health Organization: Monitor tobacco use and prevention policies; Protect people from tobacco smoke; Offer help to quit

Brendan P. McDonnell

bmcdonnell@rcsi.ie

1 Coombe Women and Infants University Hospital, Cork Street, Dublin 8, Ireland

2 Royal College of Surgeons in Ireland, 123 St Stephen's Green, Dublin 2, Ireland

3 TobaccoFree Research Institute, Focas Research Institute, DIT Kevin Street, Camden Row, Dublin 2, Ireland tobacco use; Warn about the dangers of tobacco; Enforce bans on tobacco advertising, promotion, and sponsorship; and Raise taxes on tobacco. Avoidance or evasion of tobacco taxation through the use of illicit tobacco undermines the effectiveness of public health policy, as cheaper prices for tobacco lead to increased tobacco use [2]. An example of tobacco tax avoidance is when an individual from a high-tax jurisdiction purchases tobacco products for their own use from duty-free shops or from lower tax jurisdictions. In contrast, tobacco tax evasion involves the purchase of illicitly manufactured and/or smuggled tobacco.

Large European cross-sectional surveys suggest that 4.6\% of cigarette packets in Ireland are illicit [3]. Revenue puts this figure higher, at $15 \%$ illegal and 9\% non-Irish duty paid in 2019; however, this figure is based on market research data only $[4,5]$. Despite industry claims to the contrary $[6]$, the level of illicit tobacco use is not necessarily directly correlated to tobacco taxation or price, as countries with less taxation have higher use of illicit cigarettes. Rather, it would seem to be related to supply and ease of cross-border transport, with 
countries in Eastern Europe having the highest rates of illicit tobacco use in the European Union [3, 7-9].

Cigarette smoking is a major risk factor for maternal and fetal morbidity and mortality and is associated with adverse maternal and fetal outcomes [10]. Smoking is also associated with longterm adverse consequences for the child in terms of neurological development, endocrine dysfunction, and oncogenesis [11-13]. Approximately $21 \%$ of Irish women over the age of 15 years old are smokers [14]. There is no national system which records prevalence of smoking in pregnancy in Ireland. Individual maternity hospitals have seen a decline in antenatal smoking in recent years, with one institution reporting a fall from 13.5\% in 2012 to $9.5 \%$ in 2018 [15]. Our hospital, a large tertiary referral center, delivers approximately 8500 infants annually and is the location of a randomized controlled trial of a new model of antenatal care for pregnant smokers [16].

Cigarette smoking strongly correlates with socioeconomic status. Nationally, tobacco use follows a social gradient, with smoking less common in professional and managerial strata compared to those from manual and unskilled groups [14]. The average price of a packet of twenty cigarettes in Ireland was $€ 13.50$ before Budget 2021 increased this to $€ 14$ in November 2020 [17]. The monetary value of social welfare has not risen in parity with the increasing price of tobacco. Therefore, for low-income households or those dependent on social welfare, weekly expenditure on tobacco products is an increasing burden. This may increase the appeal of illicit tobacco.

To our knowledge, there are no data on the use of illicit tobacco among pregnant women. This study asks whether pregnant women are sourcing their tobacco through illicit means in order reduce their financial burden. We also ascertained the number of cigarettes smoked, the rate of use of Roll-Your-Own (RYO) tobacco, which is cheaper than cigarettes, and the amount of money spent per week on tobacco.

\section{Methods}

This was a prospective cohort study conducted with participants of the Smoking cessation Through Optimisation of clinical care in Pregnancy (STOP) randomized controlled trial (RCT) at the Coombe Women and Infants University Hospital. This is an RCT of an antenatal smoking cessation intervention for pregnant smokers. The trial is registered as International Standard Randomized Controlled Trials Number 11214785 and began recruiting in February 2018 and was completed in late 2020 [16, 18]. Starting in April 2019, face to face interviews were conducted with a subset of pregnant women enrolled in the STOP RCT until end of trial recruitment in early March 2020. During this 11-month period, women attending the STOP clinic were informally approached in the clinic and invited to participate in the study.
Expectant women attending the Coombe for antenatal care have an unemployment rate of $19.5 \%$, which is four times the national average prior to the Coronavirus pandemic [15]. Much of the Coombe catchment area would be classified as "disadvantaged" to "very disadvantaged" based on the Pobal Deprivation Index [19].

Women attending this hospital have a booking history interview at 10-14 weeks gestation. Data is recorded onto the electronic medical record system by trained midwives using standardized question/answer fields. This questionnaire records whether a person has ever smoked, the current self-reported smoking status, and categorizes the number of cigarettes smoked per day into blocks of $1-5,6-10,11-20$, and $>20$. The patient is then asked if they currently use electronic cigarettes or if they "vape." Obstetric and neonatal outcomes were collected retrospectively from the EuroKing K2 electronic medical record system used in the hospital for medical records, annual clinical reports, and research purposes. Occupations are coded using the Irish Central Statistics Office Occupation Classification which is a modified version of the UK Standard Occupational Classification [20].

Women were asked information on the sourcing of their tobacco and their average spend per week. They were then asked to present the tobacco packaging to the interviewer. If the individual could not present the packaging, they were asked to report on the last product they purchased.

The cigarette or tobacco packs were examined for appropriate packaging, health warnings, tax stamp, and the cost of the packet as self-reported by the interviewees. The above criteria were cross referenced with examples of Irish tobacco packaging to ensure their authenticity.

If unable to present, the women self-reported on their last tobacco purchase following the protocol used by Joosens et al. [3]. The tobacco was deemed illicit if (1) it was declared by the participant to be bought from an individual selling door to door, at a local market, via a delivery service or on the street; (2) if it had an inappropriate health warning such as a health warning in a foreign language (unless purchased legally abroad or in a duty-free shop) or absence of any health warning; (3) an inappropriate tax stamp such as a foreign tax stamp (unless purchased legally abroad or in a duty-free shop) or absence of any tax stamp; or (4) the price is substantially below that of the recommended retail price-defined as a price lower than that of $70 \%$ of the lowest price of cigarettes in Ireland as defined by the WHO. An absent tax stamp alone may not be representative of illicit tobacco, as the tax stamp can sometimes be dislodged from the packet on opening.

\section{Results}

Ninety women were interviewed by the research team. Baseline maternal characteristics and socioeconomic 
grouping are outlined in Table 1. Women were divided into socioeconomic groups based on occupation. Fifty-one percent worked in professional, skilled, or non-manual employment. This compares poorly with non-smokers, $84 \%$ of whom work in professional, skilled, or non-manual employment [21]. $18.8 \%$ of participants were unemployed, a rate four times the national average before the coronavirus pandemic.

Current smoking status and number of cigarettes smoked per day are listed in Table 2. The majority of women, $76.6 \%$, were smoking less than 10 cigarettes per day. Seventeen women $(18.8 \%)$ smoked RYO tobacco with the remainder smoking factory-rolled cigarettes. The mean spend on tobacco per week was $€ 39$ (range $€ 7$ to $€ 110$ ), with the majority of participants spending between $€ 10$ and $€ 15$ per pack (Table 3). This is consistent with the average price of a pack of twenty cigarettes in Ireland. Of the three women who spent less than $€ 10$ per pack, two of these shared legal tobacco with a partner, while one purchased illicit cigarettes in bulk from a friend.

Other participants with higher spends per pack provided the correct price according to their chosen brand and size of tobacco product. Six women $(6.6 \%)$ were unable to answer how much they spend per pack as they did not buy their own tobacco. Three women (3.3\%) reported buying cigarettes at a price substantially below that of the recommended retail price. Two of these bought their cigarettes from retail units in other countries, and one in bulk from a friend.

Location of purchase or supply is listed in Table 4. Eighty-three women $(92.2 \%)$ reported purchasing their tobacco in Irish retail outlets. Three women $(3.3 \%)$ purchased them legally in other countries, while three

Table 1 Demographics and socioeconomic groupings. Age and BMI presented as mean \pm std dev

\begin{tabular}{ll}
\hline Demographics & \\
Mean age (years) & $28 \pm 5.9$ \\
Ethnicity & $100 \%$ Caucasian \\
& $90 \%$ white Irish; $10 \%$ \\
& \multicolumn{1}{c}{ other white European } \\
Planned pregnancy & $50 \%$ \\
BMI $\left(\mathrm{kg} / \mathrm{m}^{2}\right)$ & $27.2 \pm 6.2$ \\
Number of children: & None $38.8 \%$ \\
& One or more $61.2 \%$ \\
Socioeconomic group & $\boldsymbol{n}(\%)$ \\
Professional and managerial & $10(11.1)$ \\
Skilled and non-manual & $36(40)$ \\
Semi-skilled and unskilled manual & $14(15.5)$ \\
Homemaker & $11(12.2)$ \\
Full time education & $2(2.2)$ \\
Unemployed & $17(18.8)$ \\
\hline
\end{tabular}

Table 2 Number of cigarettes smoked per day

\begin{tabular}{lc}
\hline Number of cigarettes smoked per day & $n(\%)$ \\
\hline 0 cigarettes (i.e., recently quit) & $2(2.2)$ \\
$1-5$ cigarettes & $23(25.5)$ \\
$6-10$ cigarettes & $46(51.1)$ \\
$11-15$ cigarettes & $13(14.4)$ \\
$16-20$ cigarettes & $5(5.5)$ \\
$>20$ per day & $1(1.1)$ \\
\hline
\end{tabular}

(3.3\%) obtained their cigarettes from family or partner. One person $(1.1 \%)$ purchased their tobacco at a DutyFree retail unit.

When asked to present their pack in clinic, 28 participants (31.1\%) had their pack on their person. Twenty-four of the 28 women presented tobacco packs with Irish taxation stamps and four presented packs without the correct revenue stamp. These four consisted of one pack from duty free, one from another European country with the correct health warning and tax stamp of that country, and two with no tax stamps. One of the packs with no tax stamp had correct Irish health warnings and was reported as purchased in a normal Irish retail unit for the correct price. Tax stamps can sometimes become detached on opening the packet of tobacco, and it is likely that this was not illicit tobacco. However, one other pack had a missing tax stamp, no health warning, and was purchased for a significantly lower price from a friend who bought "in bulk." This pack was classed as illicit tobacco.

Forty-seven women $(52.2 \%)$ had no pack present but reported Irish health warnings and tax stamps. Three women (3.3\%) had no pack present but reported foreign health warnings and/or tax stamps. These three women purchased their tobacco legally in another European country. Twelve women $(13.3 \%)$ had no pack present and were unsure of the health warnings and tax stamps.

When asked directly, five women, $5.5 \%$, reported ever purchasing tobacco from an illicit source such as at a street market or a door to door seller. Although qualitative data was not sought at interview, most women expressed negative feelings towards illicit tobacco and perceived it as an inferior

Table 3 Spend per pack of tobacco

\begin{tabular}{lc}
\hline Spend per pack of tobacco & $n(\%)$ \\
\hline Less than €10 & $3(3.3)$ \\
$€ 10-€ 15$ & $54(60)$ \\
$€ 15.01-€ 20$ & $26(28.8)$ \\
More than $€ 20$ & $1(1.1)$ \\
Unable to provide a price & $6(6.6)$ \\
\hline
\end{tabular}


Table 4 Location of purchase

\begin{tabular}{lll}
\hline Location of purchase/supply & Taxation category & $n(\%)$ \\
\hline Irish retail unit & Legal & $83(92.2)$ \\
From family or partner & Legal & $3(3.3)$ \\
Foreign retail unit & Taxation avoidance & $3(3.3)$ \\
Duty-free shops & Taxation avoidance & $1(1.1)$ \\
Via the internet & Taxation evasion & 0 \\
Illegally, e.g., marketplace, door to door & & \\
\hline
\end{tabular}

product that is potentially even more dangerous than normal tobacco, particularly during pregnancy.

\section{Discussion}

This is a novel study examining the use of illicit tobacco among pregnant women who smoke. The strength of this study is that the women were interviewed face to face in a familiar setting by a research team known to them. All but one woman interviewed sourced their tobacco legally, with the vast majority purchasing their tobacco in normal Irish retail outlets. Four women $(4.4 \%)$ purchased their tobacco either abroad due to being nationals of other countries, or via duty free. These four women represent tobacco tax avoidance practices. A small number of women obtained their tobacco from a peer-typically a family member or partner. It was in this setting we found the single incident of illicit tobacco use. Our research contradicts tobacco industry-sponsored claims that high tobacco taxation results in higher rates of illicit tobacco use.

Women who were unable to present their pack represent a limitation, in that there is potential for error or recall bias. However, given the familiar setting and relationship established with these women over the course of the clinical trial, we feel truthful and accurate responses were given.

The low use of illicit tobacco in pregnant women contrasts with the reported rate of illicit tobacco use in the Irish general population, $4.6 \%$ [3]. This difference may be related to the relatively small number of women interviewed. $5.5 \%$ of participants had used illicit tobacco in the past.

Smoking ten cigarettes per day costs over $€ 200$ per month. The maximum social welfare payment in Ireland to an adult is $€ 812$ per month. Therefore, a significant proportion of a smoker's income is spent on cigarettes. For example, a ten cigarette per day habit would consume a quarter of monthly income while a twenty cigarette per day habit would consume half [17].

This study suggests that the majority of Irish pregnant women are sourcing their tobacco through legal means, despite the impact on their personal finances and the rising cost of tobacco products. Smoking cessation support would therefore provide significant financial benefits to these women in addition to health improvement.

Funding This work is funded by the "Friends of the Coombe" Registered Charity Number CHY 18654.

Data availability Data are available on request.

\section{Compliance with ethical standards}

Competing interests The authors declare that they have no conflict of interest.

Ethical approval Ethical approval was granted by the Coombe Women \& Infants University Hospital Research and Ethics Committee (Study No. 25-2017, amended February 2019). Written consent to participate and consent to publish were obtained. All research was carried out in accordance with the Code of Ethics of the World Medical Association (Declaration of Helsinki).

\section{References}

1. WHO (2003) WHO Framework Convention on Tobacco Control. Geneva

2. Ross H, Blecher E, Yan L, Hyland A (2011) Do cigarette prices motivate smokers to quit? New evidence from the ITC survey. Addiction. 106(3):609-619

3. Joossens L, Lugo A, La Vecchia C, Gilmore AB, Clancy L, Gallus S (2014) Illicit cigarettes and hand-rolled tobacco in 18 European countries: a cross-sectional survey. Tob Control 23(E1)

4. Revenue (2019) Illegal Tobacco Products Research Surveys 2019. [cited 2020 Dec 3]. Available from: https://www.revenue.ie/en/ corporate/documents/research/tobacco-surveys-2019.pdf

5. Revenue (2019) Tobacco Products Research Surveys Methodology Note. [cited 2020 Dec 3]. Available from: https:// www.revenue.ie/en/corporate/documents/research/surveymethodology-note.pdf

6. Grant-Thornton (2016) Illicit Trade 2015-2016 Implications for the Irish economy. Available from: https:/www.grantthornton.ie/ globalassets/1.-member-firms/ireland/insights/publications/grantthornton\%2D\%2D-illicit-trade-2015-2016..pdf

7. Driezen P, Thompson ME, Fong GT et al (2018) Cross-border purchasing of cigarettes among smokers in Six Countries of the EUREST-PLUS ITC Europe Surveys. Tob Induc Dis 16:A13

8. Nagelhout GE, van den Putte B, Allwright S et al (2014) Socioeconomic and country variations in cross-border cigarette purchasing as tobacco tax avoidance strategy. Findings from the ITC Europe Surveys. Tob Control 23(Suppl 1(0 1)):i30-i38

9. Agaku IT, Blecher E, Filippidis FT, Omaduvie UT, Vozikis A, Vardavas CI (2016 May) Impact of cigarette price differences across the entire European Union on cross-border purchase of tobacco products among adult cigarette smokers. Tob Control 25(3): $333-340$

10. Blackburn S. (2014) Maternal, fetal, \& neonatal physiology. 4th ed. Elsevier Health Sciences

11. Fergusson D, Horwood L, Lynskey M (1993) Maternal smoking before and after pregnancy: effects on behavioral outcomes in middle childhood. Pediatrics. 92(6):815-822 
12. Ortega-García JA, Martin M, López-Fernández MT et al (2010) Transgenerational tobacco smoke exposure and childhood cancer: an observational study. J Paediatr Child Health 46(6):291-295

13. Lisboa P, Oliveira E, Moura E (2012) Obesity and endocrine dysfunction programmed by maternal smoking in pregnancy and lactation. Front Physiol 3:437

14. The State of Tobacco Control in Ireland (2018) Dublin: Health Service Executive Tobacco Free Ireland Program

15. Coombe Women \& Infants University Hospital (2018) Annual clinical report. Dublin

16. McDonnell BP, Dicker P, Keogan S et al (2019) Smoking cessation through optimisation of clinical care in pregnancy: the STOP randomised controlled trial. Trials. 20(1):1-9

17. Central Statistics Office (2020) National Average Price (Euro) for selected consumer items. [cited 2020 Jun 24]. Available from: https://statbank.cso.ie/multiquicktables/quickTables.aspx?id= cpm04_cpm12
18. McDonnell BP (2018) Can a specialised antenatal clinic help pregnant women quit smoking and reduce the risk of complications for mother and baby? ISRCTN11214785. [cited 2020 Mar 5]. Available from: https://doi.org/10.1186/ISRCTN11214785

19. Pobal (2016) Pobal Deprivation Index. [cited 2019 Aug 1]. Available from: https://maps.pobal.ie/WebApps/ DeprivationIndices/index.html

20. Central Statistics Office (2016) Standard Employment Status Classification. Dublin

21. McDonnell B, Dicker P, Regan C (2020) Electronic cigarettes and obstetric outcomes: a prospective observational study. BJOG An Int J Obstet Gynaecol 127(6):750-756

Publisher's note Springer Nature remains neutral with regard to jurisdictional claims in published maps and institutional affiliations. 